\title{
Detection of Dehydration by Using Volume Kinetics
}

Joachim Zdolsek, Yuhong Li and Robert Hahn

\section{Linköping University Post Print}

\section{Tweet}

N.B.: When citing this work, cite the original article.

Original Publication:

Joachim Zdolsek, Yuhong Li and Robert Hahn, Detection of Dehydration by Using Volume Kinetics, 2012, Anesthesia and Analgesia, (115), 4, 814-822.

http://dx.doi.org/10.1213/ANE.0b013e318261f6ba

Copyright: Lippincott, Williams \& Wilkins http://www.lww.com/

Postprint available at: Linköping University Electronic Press

http://urn.kb.se/resolve?urn=urn:nbn:se:liu:diva-85198 


\title{
Detection of Mild Dehydration in Volunteers by Using Volume Kinetics
}

\author{
Joachim Zdolsek, Yuhong Li, and Robert G. Hahn \\ Department of Anesthesia, Faculty of Health Sciences, \\ Linköping University, Linköping, Sweden \\ Secondary address for Dr. Li: Department of Anesthesia, \\ First Affiliated Hospital, College of Medicine, \\ Zhejiang University, Hangzhou, People's Republic of China
}

\author{
Corresponding author: \\ Robert Hahn MD, PhD \\ Department of Anesthesia \\ Linköping University Hospital \\ 58585 Linköping, Sweden \\ Phone: +46739660972 \\ Fax: +46855024671 \\ E-mail: r.hahn@telia.com
}

Running head: Kinetic analysis of dehydration

Author's contributions: Zdolsek planned and organized the experiments. Li conducted the experiments. Hahn made the study design, completed the data analysis, and wrote the manuscript.

Implications statement: A study of volunteers shows that dehydration of $2 \%$ of body weight can be detected from the dilution of the blood hemoglobin concentration following an infusion of only $5 \mathrm{ml} / \mathrm{kg}$ of Ringer's solution. 


\section{Abstract}

Background: Patients admitted to surgery may be dehydrated, which is difficult to diagnose except when it is severe (>5\% of the body weight). This study hypothesizes that modest dehydration can be detected by kinetic analysis of the blood hemoglobin (Hgb) concentration following a bolus infusion of crystalloid fluid.

Methods: Four series of experiments were performed on 10 conscious, healthy male volunteers. Separated by at least two days, they received $5 \mathrm{ml} / \mathrm{kg}$ or $10 \mathrm{ml} / \mathrm{kg}$ of acetated Ringer's over 15 min. Before starting half of the intravenous infusions, volume depletion amounting to $1.5-2.0 \mathrm{~L}$ (approximately $2 \%$ of body weight) was induced with furosemide. The elimination clearance and the half-life of the infused fluid were calculated based on blood Hgb over $120 \mathrm{~min}$. The perfusion index and the pleth variability index were monitored by pulse oximetry following a change of body position.

Results and Discussion: Dehydration decreased the elimination clearance of acetated Ringer's [median $\left(25^{\text {th }}-75^{\text {th }}\right.$ percentile $)$ from $1.84(1.23-2.57)$ to $0.53(0.41-0.79)$ $\mathrm{ml} / \mathrm{kg} / \mathrm{min}$ (Wilcoxon's matched-pair test $P<0.001$ ) and increased the half-life from 23 (12-37) to $76(57-101)$ minutes $(P<0.001)$. The smaller infusion, $5 \mathrm{ml} / \mathrm{kg}$, fully discriminated between experiments performed in the euhydrated and dehydrated states, whereas the urinary excretion provided a less reliable indication of hydration status. Dehydration decreased the perfusion index but did not affect the pleth variability index.

Conclusion: Dehydration amounting to $2 \%$ of the body weight could be detected from the elimination clearance and the half-life of an infusion of $5 \mathrm{ml} / \mathrm{kg}$ of Ringer's solution.

\section{Word count: 3,974}

Keywords: blood hemoglobin, pharmacokinetics model, dehydration, fluids, IV 


\section{Introduction}

To maintain hydration status in balance is a key challenge in the treatment of diseases that involve excessive fluid loss. Normal hydration is also important in patients scheduled for anesthesia and surgery. Serious dehydration, particularly if dominated by volume losses from the extracellular fluid (ECF) space, can result in increased hemodynamic effects of anesthetic drugs, poor tissue perfusion, and oliguria. The consequences of moderate dehydration are less well known, although the administration of approximately $2 \mathrm{~L}$ more or less of crystalloid fluid during abdominal surgery affects the incidence of postoperative complications. ${ }^{1}$

The judgment of whether dehydration is present is usually based on physical inspection of skin turgor. A rise in the blood hemoglobin ( $\mathrm{Hgb})$ or serum creatinine concentration is consistent with dehydration, but a recent control measurement might not be available. Clinical methods, such as skin turgor, may disclose dehydration amounting to $5 \%-10 \%$ of the body weight, but it is unlikely that they can reliably detect smaller variations in fluid balance in preoperative surgical patients.

The primary hypothesis of the present exploratory study was that volume kinetic analysis of a small amount of crystalloid fluid could be used to detect fluid losses amounting to $2 \%$ of body weight. The kinetic analysis used serial analyses of the blood $\mathrm{Hgb}$ concentration to quantify the distribution and elimination of the infused fluid. ${ }^{2-8}$

A secondary hypothesis was that dehydration could be indicated by non-invasive monitoring of the pleth variability index (PVI) using pulse oximetry upon a change of body position. ${ }^{9-12}$ For this purpose, conscious volunteers were studied both when being normo-hydrated and when dehydration had been induced by intravenous furosemide. 


\section{Subjects and Methods}

Forty experiments were performed on 10 male volunteers with a mean age of 22 years (range 19-37), a body weight of $80 \mathrm{~kg}$ (range 75-100), and a body mass index of $24.9 \mathrm{~kg} / \mathrm{m}^{2}$ (range 21.8-28.4). None of the subjects had any disease or took daily medication. The Ethics Committee of Linköping University approved the protocol (Ref. M114-09, ClinicalTrials.gov Identifier NCT01062776). Each volunteer gave his consent for participation after being informed about the study both orally and in writing.

\section{Procedure}

Table 1shows a flow diagram for the study. On the day of the experiment, the volunteers had fasted since midnight and then imbibed $800 \mathrm{ml}$ (approximately $10 \mathrm{ml} / \mathrm{kg}$ ) of water at 6:00 a.m. The purpose of the fluid intake was to correct any pre-existing dehydration while allowing the body time to void and to arrive at its desired degree of hydration two hours later. The experiments started at 8:00 a.m. in a single room at the Department of Intensive Care at Linköping University Hospital. To achieve maximum comfort, an OPN Thermal Ceiling radiant warmer (Aragona Medical, River Vale, NJ) had been placed about $1 \mathrm{~m}$ above the bed.

Fluid infusions. A cannula was placed in the cubital vein of one arm to infuse fluid and another cannula was inserted in the other arm for sampling blood. Plasma volume expansion was then induced by administering acetated Ringer's solution (Baxter Medical AB, Kista, Sweden) intravenously over $15 \mathrm{~min}$ by using an infusion pump (Volumat MC Agilia, Fresenius Kabi, Bad Homburg, Germany).

All 10 volunteers underwent four experiments in a random order determined by the sealed envelope method, and separated by at least two days. The experiments were designed as follows:

(1) Infusion of $5 \mathrm{ml} / \mathrm{kg}$ of acetated Ringer's solution in the euhydrated state, 
(2) Infusion of $10 \mathrm{ml} / \mathrm{kg}$ of acetated Ringer's solution in the euhydrated state,

(3) Infusion of $5 \mathrm{ml} / \mathrm{kg}$ of acetated Ringer's solution in the dehydrated state, and

(4) Infusion of $10 \mathrm{ml} / \mathrm{kg}$ of acetated Ringer's solution in the dehydrated state.

The Ringer's solution had the following ionic content: sodium 130, chloride 110, acetate 30 , potassium 4 , calcium 2 , and magnesium $1 \mathrm{mmol} / \mathrm{L}$.

The fluid bag was kept on the radiant warmer above the bed to maintain a temperature of $27^{\circ} \mathrm{C}-30^{\circ} \mathrm{C}$ when entering the volunteer.

Dehydration procedure. Volume depletion was induced by repeated small intravenous doses of $5 \mathrm{mg}$ of furosemide (Furix $10 \mathrm{mg} / \mathrm{ml}$, Nycomed, Stockholm, Sweden) provided every 10-30 min until the urinary excretion amounted to between 1.5 and $2.0 \mathrm{~L}$. Sixty minutes elapsed between the last dose of furosemide (total dose $25 \mathrm{mg}$, range 15-35) and the infusion of Ringer's.

The volunteers were weighed to the nearest $0.01 \mathrm{~kg}$ on an electronic scale (Vetek $\mathrm{AB}$, Väddo, Sweden) just before, and at the end of, the dehydration period.

Fluid recruitment maneuver. To examine whether pulse oximetry could be used to detect dehydration, three pulse oximeter variables were recorded every $5 \mathrm{~min}$ before and after a change in body position from semi-standing $(0-10 \mathrm{~min})$ to the recumbent position (11-25 min), a maneuver that relieves hypovolemia by recruiting interstitial fluid from the legs to increase the plasma volume by approximately $6 \%$ within 30 min. ${ }^{13}$

The test was performed as the first part of each experiment and, in Experiments 2 and 4, after dehydration when the volunteer awaited an infusion of Ringer's solution (Table 1). "Semi-standing" meant that the volunteer was standing up but leaning against the bed, a position chosen to safeguard against fainting in the presence of dehydration.

\section{Measurements}

Blood sampling. During the fluid infusion experiments, venous blood (4 ml) was withdrawn to measure the Hgb concentration and the hematocrit on a CELL-DYN Sapphire (Abbott Diagnostics, Abbott Park, IL). Sampling was performed every 5 min 
during the first $50 \mathrm{~min}$, and then at 60, 70, 90, 105, and $120 \mathrm{~min}$. The baseline sample was drawn in duplicate, and the mean of the two concentrations was used in subsequent calculations. The differences between the two baseline samples for all 40 experiments were used to calculate the coefficient of variation (precision) for the Hgb measurement, which was $0.8 \% .{ }^{14}$ A total of 17 samples were taken. A small discard volume of blood was drawn before each blood collection to preclude an admixture of rinsing solution, and $2 \mathrm{ml}$ of $0.9 \%$ saline was then injected to prevent clotting.

Urine collection. The subjects voided when they entered the study room and this urine was discarded. They voided freely in the lying position throughout the experiments. The total volume was recorded when the volunteers emptied their bladders completely at the end of the dehydration period and at the end of the infusion experiment.

Pulse oximetry. A Radical- $7^{\mathrm{TM}}$ pulse oximeter (Masimo Corp., Irvine, CA) was applied to the index or middle finger of one hand and it was left in the same place throughout the experiment (software version SET V7.4.0.9, Handheld R.7.7.1.0 and D-station R5.1.2.7). A repeated-use probe with a programmed obsolescence of 60 hours was used. This apparatus measured the perfusion index (PI), venous Hgb concentration, and the pleth variability index (PVI). The display was set to average the data every six seconds.

PI represents the pulse amplitude. PVI is the breath-induced variation in PI and is calculated as $\left(\mathrm{PI}_{\max }-\mathrm{PI}_{\min }\right) / \mathrm{PI}_{\max }$ over several respiratory cycles. ${ }^{9}$ Upon inclusion in the study, the volunteers were tested to meet a minimum requirement of PI>2 (maximum value 14) as peripheral vasoconstriction distorts the non-invasive Hgb analysis.

Pulse oximetry data are given for the fluid recruitment maneuver only. The relationship between the invasive and non-invasive $\mathrm{Hgb}$ analyses obtained during the infusion experiments have been reported previously and were found to be inadequate for use in volume kinetic analysis. ${ }^{15}$ 


\section{Kinetic analysis}

Volume kinetic analyses were performed according to one-volume and two-volume models (Fig. 1). In the first one, the infusion of fluid at the rate $R_{\mathrm{o}}$ expanded the functional body fluid volume $V_{c}$ to $v_{c}$. Removal of the fluid occurred by means of baseline fluid losses $\left(\mathrm{Cl}_{\mathrm{o}}\right)$ that were pre-set to $0.4 \mathrm{ml} / \mathrm{min}$, and by a dilution-dependent elimination clearance mechanism $(C l){ }^{2}$ The differential equation for the model is:

$$
\frac{d v_{c}}{d t}=R_{o}-C l_{o}-C l \frac{v_{c}(t)-V_{c}}{V_{c}}
$$

The two-volume model added a peripheral compartment $V_{\mathrm{p}}$ that expanded to $v_{\mathrm{p}}$ by exchanging fluid with $v_{\mathrm{c}}$ at a rate governed by a distribution clearance, $C l_{\mathrm{d}}$. The differential equations for this model are:

$$
\begin{aligned}
& \frac{d \nu_{\mathrm{c}}}{d t}=R_{\mathrm{o}}-C l_{\mathrm{o}}-C l \frac{\left(\nu_{\mathrm{c}}(t)-V_{\mathrm{c}}\right)}{V_{\mathrm{c}}}-C l_{\mathrm{d}}\left[\frac{\left(\nu_{\mathrm{c}}(t)-V_{\mathrm{c}}\right)}{V_{\mathrm{c}}}-\frac{\left(\nu_{\mathrm{p}}(t)-V_{\mathrm{p}}\right)}{V_{\mathrm{p}}}\right] \\
& \frac{d \nu_{\mathrm{p}}}{d t}=C l d\left\lfloor\frac{\left(\nu_{\mathrm{c}}(t)-V_{\mathrm{c}}\right)}{V_{\mathrm{c}}}-\frac{\left(\nu_{\mathrm{p}}(t)-V_{\mathrm{p}}\right)}{V_{\mathrm{p}}}\right\rfloor
\end{aligned}
$$

The Hgb-derived fractional plasma dilution was used as the input $\operatorname{Hgb}(t)$ at time $t$ :

$$
\frac{v_{c}(t)-V_{c}}{V_{c}}=\frac{\frac{\mathrm{Hgb}}{\operatorname{Hgb}(t)} \pm 1}{1-\mathrm{Hct}}
$$

where $\mathrm{Hgb}$ and Hct are the blood Hgb concentration and the hematocrit at baseline, respectively. A correction for the loss of sampled Hgb was applied. ${ }^{7}$ Previous work has defined these models ${ }^{2}$ and given analytical ${ }^{3}$ and matrix solutions ${ }^{4}$ to the equations used.

Curve-fitting was performed by least-squares regression, based on the analytical solutions to the differential equations, and programmed into the computer program Matlab 4.2 (Math Works Inc., Natick, MA). No weights were used because the analyses were based blood $\mathrm{Hgb}$ changes of between 0 and 7-8\% in which span the analytical precision of the Hgb assay was practically identical. 
Three approaches were used for the presentation: (1) all curves analyzed by the one-volume model based on all 16 data points, (2) all curves analyzed by the optimal model, being either the one- or two-volume model as determined by the $F \operatorname{test}^{2-4}$, and (3) the one-volume model based on 4 data points only.

For the one-volume model, the output was the optimal estimates of $V_{\mathrm{c}}$ and $C l$. The elimination half-life of infused fluid $\left(T_{1 / 2}\right)$ was calculated as $0.693 \mathrm{~V} / \mathrm{Cl}$. For the two-volume model, the output parameters were $V_{\mathrm{c}}, V_{\mathrm{p}}, C l$, and $C l_{\mathrm{d}}$. The elimination $T_{1 / 2}$ was $0.693 \mathrm{~V}_{\mathrm{c}} / \mathrm{Cl}$.

The renal clearance $\left(C l_{\mathrm{r}}\right)$ of the infused fluid was obtained as the urine volume excreted during the two-hour infusion experiment divided by the area under the plasma dilution-time curve (AUC). ${ }^{2,4}$ The $C l_{\mathrm{r}}$ was calculated for only 38 experiments since two volunteers were unable to void at the end of the $10 \mathrm{ml} / \mathrm{kg}$ infusions during euhydration.

Hence, there were four clearances to consider. $C l_{\mathrm{o}}$ and $C l_{\mathrm{r}}$ were model-independent while there was one elimination $\mathrm{Cl}$ in the one-volume model and another in the two-volume model. The former $\mathrm{Cl}$ is higher as the one-volume model is expected to be statistically justified when elimination is efficient (resulting in high urinary excretion). The elimination $\mathrm{Cl}$ might also be higher in the one-volume model because some fluid has distributed to a peripheral compartment (by the mechanism $C l_{\mathrm{d}}$ ) although not in enough amounts to change the slope of the dilution-time curve markedly. If the urine collection is complete, $\mathrm{Cl}_{\mathrm{r}}$ is close to the $\mathrm{Cl}$ of the optimal model ${ }^{16}$ except during surgery when extravascular retention of fluid might occur so that $\mathrm{Cl}_{\mathrm{r}}<\mathrm{Cl}^{7}$

The result of the very first experiment in the series deviated markedly from the others, showing a very low fluid clearance despite euhydration. The volunteer had been up all night before this experiment session and had been fasting for a period; both factors were unknown to us at the time. Therefore, this experiment was repeated several months later when the volunteer followed the instructions for normal sleep and food intake.

\section{Statistics}


The results are given as the mean (SD), except when there is a skewed distribution when data is reported as the median $\left(25^{\text {th }}-75^{\text {th }}\right.$ percentiles $)$.

Two-way ANOVA was used to examine whether the kinetic parameters differed depending on the infused fluid volume or dehydration. Logarithm-transformed $\left(\mathrm{Cl}, \mathrm{Cl}_{r}\right.$ and $T_{1 / 2}$ ) or square root-transformed data (urine and ratio urine/infused fluid) were applied if the distribution of the data were skewed. After transformation the distribution was close to normal.

Changes were reported as the median and the $95 \%$ confidence interval (CI) for the difference between paired data.

Differences between paired and unpaired samples were examined by the Wilcoxon matched-pair test and the Mann-Whitney U test, respectively.

Logistic regression was used to select the probability range where sensitivity and specificity of various kinetic parameters to indicate dehydration were as similar as possible. The middle of this range was selected as cut-off point, which was then used to calculate the $95 \%$ CI for the sensitivity and specificity in question.

The study was powered $(90 \%)$ based on retrospective data ${ }^{17}$ in which the blood $\mathrm{Hgb}$ was $96.9 \%$ (SD 2.9) of baseline 30 minutes after the end of the 30-minute infusion of Ringer's solution in euhydrated volunteers. The corresponding Hgb level was 91.4\% (3.1) when the same volunteers underwent the infusion experiment again after an overnight fast. The current study strived to detect a difference of 5\% in Hgb levels, depending on the hydration status at $60 \mathrm{~min}$, with a power of $90 \%$ and $P<0.05$.

The $F$ test determined whether the one-volume or two-volume kinetic model was statistically justified. $.^{2-4} P<0.05$ was considered statistically significant. 


\section{Results}

\section{Dehydration}

Furosemide promoted urinary excretion amounting to $1.71(0.26) \mathrm{L}$ (range 1.38$2.43 \mathrm{~L}$ ), which represented $2.1(0.4) \%$ of the body weight (range 1.5-3.0).

The body weight decreased by $2.0(0.4) \mathrm{kg}$ (range 1.5-3.0) from the dehydration procedure. The difference between measured weight loss and measured urine excretion is due to evaporation and metabolism $\left(\mathrm{Cl}_{\mathrm{o}}\right)$.

The Hgb concentration increased by 7.9\% (SD 2.1, range 2.1-11.5) during the dehydration procedure. Assuming that the blood volume amounts to $7.5 \%$ of the body weight, this $\mathrm{Hgb}$ change corresponds to a reduction of the blood volume by $0.50(0.13) \mathrm{L}$. Hence, 30 (9) \% of the voided volume was derived from the blood. There were no differences between the $5 \mathrm{ml} / \mathrm{kg}$ and $10 \mathrm{ml} / \mathrm{kg}$ experiments with respect to these data.

\section{One-volume model}

Dehydration reduced the elimination $\mathrm{Cl}$ by more than half (median ratio $0.36 ; 95 \%$ CI 0.25-0.40) and more than doubled $T_{1 / 2}$ (mean 3.3, 95\% CI 2.5-6.2).

$T_{1 / 2}$ was 23 minutes in euhydration and 76 minutes in dehydration (Wilcoxon's matched-pair test $P<0.001$; Table 2).

Two-way ANOVA showed that dehydration $(P<0.001)$, but not the infused volume (being 5 or $10 \mathrm{ml} / \mathrm{kg}$ ), had a statistically significant influence on $\mathrm{Cl}$ and $T_{1 / 2}$. Contrast estimates yielded that dehydration decreased $\mathrm{Cl}$ by 1.49 (95\% CI $0.90-2.08) \mathrm{ml} / \mathrm{min} / \mathrm{kg}$ and increased $T_{1 / 2}$ by 67 (38-96) minutes. The non-significant effect of the larger fluid volume consisted in a decrease of $C l$ by $0.15([-0.44]-0.75) \mathrm{ml} / \mathrm{min} / \mathrm{kg}$ and of $T_{1 / 2}$ by 10 ([-19]-40) minutes.

The best capacity to distinguish dehydrated from euhydrated volunteers was 
obtained when parameters were derived from the $5 \mathrm{ml} / \mathrm{kg}$ experiments (Figs. 2A, B). With optimal cut-off points, there was complete separation between the data on $\mathrm{Cl}$ and $T_{1 / 2}$ depending on the state of hydration (Table 3). The sensitivity and specificity were at least $10 \%$ lower with the infusion of $10 \mathrm{ml} / \mathrm{kg}$.

\section{Optimal kinetic model}

The two-volume kinetic model was statistically justified (by the $F$ test) in 22 of the 40 experiments (one in Group 1, five in Group 2, and eight each in Groups 3 and 4). The one-volume model was appropriate in the other 18 experiments (Table 2).

Dehydration $(P<0.001)$, but not the volume of infused fluid $(P=0.45-0.82)$, had a statistically significant influence on $\mathrm{Cl}$ and $T_{1 / 2}$ when the data from the optimal model in each experiment were pooled (two-way ANOVA; Figs. 3, 4).

Using a cut-off point of $40 \mathrm{~min}$, the $T_{1 / 2}$ of the pooled optimal model fully discriminated between euhydration and dehydration when $5 \mathrm{ml} / \mathrm{kg}$ had been infused (Fig. 2C). For the infusion of $10 \mathrm{ml} / \mathrm{kg}$, the sensitivity and specificity were only $83 \%$ and $80 \%$, respectively.

\section{Urine-derived parameters}

The renal clearance $\left(C l_{\mathrm{r}}\right)$ and the excreted/infused fluid ratio were both lower in the presence of dehydration $(P<0.0001$ and $P<0.03)$ and with the larger fluid volume infusion $(P<0.003$ and $P<0.01$; two-way ANOVA; Table 2).

$C l_{\mathrm{r}}$ readily distinguished between euhydration and dehydration (Table 3), while the excreted urine volume alone showed sensitivity and specificity of only $60 \%-70 \%$.

\section{Four-point analysis}

Comparisons of the plasma dilution in euhydration and dehydration suggest that the fractional plasma dilution values are separated by the greatest amount about $60 \mathrm{~min}$ 
following the completion of the 15-min fluid infusion (Fig. 4C and D). The Hgb concentration was then $98.2 \%$ (mean) of baseline in euhydration and $95.8 \%$ in dehydration (Wilcoxon matched-pair test, $P<0.001$ ).

The one-volume kinetic analysis was then repeated but based on only the four points in time when the within-series and between-series differences in $\mathrm{Hgb}$ concentration were greatest $(0,15,60$, and $70 \mathrm{~min})$. Here, $\mathrm{V}$ and $\mathrm{Cl}$ attained $9 \%$ and $18 \%$ lower values than in the 16-point analysis, but the capacity of the kinetic model to identify dehydration of approximately $2 \%$ was largely retained (Table 3 ).

The difference between the blood Hgb level at 60-70 min and the baseline value could identify dehydration as well as the four-point kinetic analysis (Table 3).

\section{Pulse oximetry}

A comparison between the pulse oximetry variables obtained at baseline of the fluid recruitment maneuver performed before and after dehydration (in Experiments 3 and 4) showed that the dehydration procedure decreased the PI while the Hgb increased (both $P<0.01)$; the PVI was unchanged.

The non-invasive PI, Hgb, and PVI showed the same pattern upon change of body position regardless of hydration status. The only consistent change afterward was a

progressive decrease of the $\mathrm{Hgb}$ concentration that eventually reached 5\%-6\% (repeated-measures ANOVA $P<0.001$; Fig. 5). 


\section{Discussion}

The results showed that kinetic analysis of a small bolus infusion of Ringer's solution could be used to disclose that a healthy volunteer was volume depleted by an average of $2.1 \%$ of the body weight. $C l$ and $T_{1 / 2}$ discriminated well between the fluid infusions that were performed in the euhydrated and dehydrated states. The smaller infusion $(5 \mathrm{ml} / \mathrm{kg}$ ) yielded a more reliable discrimination than the larger one $(10 \mathrm{ml} / \mathrm{kg})$.

This novel approach is based on the belief that the volume status can be determined by studying how the body handles a fluid challenge. ${ }^{17}$ Euhydration results in an effort to regain the pre-infusion hydration level. In dehydration, the body retains infused fluid, which lowers $C l$ and prolongs $T_{1 / 2}$ for acetated Ringer's.

Previous work has suggested this to be the case. The $T_{1 / 2}$ of crystalloid fluid was only half as long in semi-fasting volunteers ${ }^{18}$ and laparoscopic patients ${ }^{19}$ when volume depletion was prevented by a previous infusion of the same fluid (15 versus 28 min and 19 versus $38 \mathrm{~min}$, respectively). In fasting volunteers subjected to hemorrhage, the $T_{1 / 2}$ of acetated Ringer's solution increased from $22 \mathrm{~min}$ (no hemorrhage) to $45 \mathrm{~min}(500 \mathrm{ml})$ and

$62 \mathrm{~min}(900 \mathrm{ml}) .^{5}$ However, the administered fluid volumes in those studies were 2-5 times larger than in the present study.

Tracer methods for measuring body fluid volumes, such as deuterium and bromide, have a precision of $1 \%-2 \%$ if carried out carefully ${ }^{20}$ but they involve expensive analytical procedures and may require very long mixing times. Moreover, they do not provide information about the hydration level the body strives to maintain. Clinical methods, such as assessment of skin turgor and measurement of serum osmolality, are not sensitive enough to detect minor deficits in body fluid volume.

The dehydration test presented here overcomes most of these problems, which makes our approach of interest for research. Less frequent blood sampling than the 16 points used in this exploratory study would be desirable to reach clinical efficacy. Interestingly, useful results seem to have been obtained from only four samples, and two 
samples indicating a shift of the Hgb baseline may suffice to detect dehydration (Table 3). However, with fewer samples, the results will be more sensitive to occasional errors in sampling technique and analysis of the relatively minor changes in Hgb concentration studied here. On the other hand, the relatively long period of time (60 minutes) between the first and the second blood sample cannot be significantly shortened (Fig. 4C, D).

The choice of dehydration method and kinetic model deserves a comment. Between $50 \%$ and $70 \%$ of patients require blood volume optimization before surgery, regardless of whether they fast overnight or ingest fluid preoperatively; ${ }^{21-23}$ and the blood volume is greatly affected by changes in the ECF volume. ${ }^{24}$ This explains our use of a better method of inducing dehydration than fasting overnight. Euhydration at baseline was ensured by letting each volunteer drink $800 \mathrm{ml}$ of tap water and giving him 2 hours to excrete any excess fluid; controlled dehydration was induced by furosemide. As the plasma constitutes $1 / 3$ of the expandable ECF volume, ${ }^{2}$ the rise in $\mathrm{Hgb}$ concentration during the dehydration procedure confirms that furosemide primarily reduced the ECF volume. Hence, the type of dehydration studied here better reflects fluid losses by vomiting and diarrhea (volume depletion) than by evaporation alone.

The one-volume model offers simplicity and stability, and therefore, clinical applicability. The kinetics may also be handled by adding a second compartment to the model. The bi-exponential form of the plasma dilution-time curve is typical of fluid retention and can be expected in hypovolemia, ${ }^{5}$ anesthesia, ${ }^{8}$ and in anesthesia and surgery. ${ }^{7}$ Several of the present experiments with $10 \mathrm{ml} / \mathrm{kg}$ showed the bi-exponential form, as did most curves collected during dehydration.

The present work reports the ability of both the one-volume and the statistically justified (optimal) model to detect dehydration. The two-volume model, which overall proved to be optimal in more than half of the experiments, yielded $15 \%$ longer elimination $T_{1 / 2}$ for acetated Ringer's solution than the one-volume model did. As the two-volume model was most common in dehydration, the difference in $T_{1 / 2}$ between eu- and dehydration increased when also considering the two-volume model. Although the 
statistical comparison between the pooled $C l$ and $T_{1 / 2}$ can be questioned on theoretical grounds, the data disclose the marked differences in kinetic parameter values that will be found when studying the hydration status of a volunteer by using the optimal model. They also illustrate that the $T_{1 / 2}$ of Ringer's exceeding 40 min serves well as a cut-off point between euhydration and dehydration, regardless of the choice of volume kinetic model. Even the model-independent $C l_{\mathrm{r}}$ solved the task well while the urinary excretion alone was hardly useful. Table 3 shows future investigators the sensitivity and specificity of kinetic parameters that are capable of detecting dehydration.

Infusing a large fluid volume causes greater depression of the Hgb level but does not seem to improve the usefulness of the dehydration test. ${ }^{17}$ The reason might be efficient elimination of small volumes of fluid in euhydrated volunteers. The urinary excretion even slightly exceeded the infused volume after 2 hours of the experiment with $5 \mathrm{ml} / \mathrm{kg}$ (data not shown), which resulted in a high elimination $\mathrm{Cl}$. Here, there was a marked predominance of the one-volume model over the two-volume model (relationship 9/1), which makes peripheral accumulation of fluid less likely. Dehydration-induced renal conservation of fluid apparently contrasted very well and consistently against high-elimination $\mathrm{Cl}$.

The secondary hypothesis was that pulse oximetry could serve as a tool to reveal dehydration. This was not possible with the approaches used here. Reduction of body water changed the baseline for PI and Hgb, but the values differed too much between individuals to be useful as a test of dehydration (Fig. 5).

The fluid recruitment maneuver, which consisted in a change of body position from semi-standing to lying down, was designed to disclose relative differences in the degree of capillary refill depending on hydration. The similar Hgb responses to this maneuver are consistent with the expectation that furosemide would dehydrate the plasma and the interstitial fluid volumes to a similar degree. An extension of the follow-up time after the change in body position could possibly have shown a dehydration-dependent difference in Hgb concentration, just as it did after the fluid infusion. On the other hand, 
the non-invasive $\mathrm{Hgb}$ technology - in contrast to invasive laboratory analysis of $\mathrm{Hgb}-$ does not yet offer the precision required to capture small $\mathrm{Hgb}$ differences in individuals. ${ }^{15}$

Interest has been focused on the PVI as an index of fluid responsiveness during mechanical ventilation, ${ }^{9,10}$ and although the PVI is a less precise measure, it seems to work in the conscious state as well. ${ }^{11,12}$ However, we found no difference in the baseline PVI and no difference in the PVI response to the fluid recruitment maneuver that depended on the state of hydration.

The present study has a proof-on-concept design and challenges whether volume kinetics can detect dehydration and, if so, how much infusion fluid would be needed to find out. The size of the body fluid space(s) expanded by an infusion can apparently not detect dehydration, but elimination parameters can. Moreover, only a small volume of fluid needs to be infused. Future studies with other designs are needed to examine whether volume kinetics can discriminate between variable degrees of dehydration. The test also needs careful validation in patients with vascular or renal disease.

Limitations include the necessity for blood sampling to distinguish safely dehydrated from euhydrated volunteers. Infusions made in the euhydrated state began at 8:30 a.m., and in the presence of dehydration, they began at 11:00 a.m. A bladder catheter was not used, which could have improved the quality of the urine data. The repeated experiment shows that aberrant results could be produced by an abnormal diurnal rhythm or lifestyle. Drobin's single-volume model $^{25}$ was first fitted to the data but required stabilization from the urinary excretion values to work when based on only 16 samples.

The perceived role of the dehydration test is in the preoperative setting. In adults awaiting hernia surgery after an overnight fast, half of the patients had a $T_{1 / 2}$ of Ringer's exceeding $40 \mathrm{~min},{ }^{26}$ which is a likely incidence. The test is unsuitable for application during general anesthesia and surgery as other mechanisms greatly prolong the $T_{1 / 2}$ of acetated Ringer's under those conditions. ${ }^{2,7,8,27}$ Moreover, the fluid chosen for the test must be retained if the kidneys sense dehydration but excreted if they do not. Therefore, colloid fluids, or blood, are not viable options. 
If the test shows that a patient is dehydrated the rational treatment is to replace the missing volume by oral or intravenous fluid before anesthesia is induced. Alternatively, those who are dehydrated may be given more fluid perioperatively to maintain organ perfusion. In contrast, patients who are euhydrated should receive relatively less fluid to avoid tissue edema, as the body's capacity to excrete a surplus of crystalloid fluid is very poor during anesthesia and surgery. ${ }^{2}$ The dehydration test could provide the anesthesiologist with the information needed to individualize the fluid therapy in this way. However, it is unclear at present whether such strategy would help to reduce the complication rate or hospital time. The requirement for invasive sampling also contributes to our belief that the dehydration test will primarily be used for research.

In conclusion, the half-life of a small volume of crystalloid fluid $(5 \mathrm{ml} / \mathrm{kg})$ discriminated between eu- and dehydration in healthy volunteers. This finding opens a possibility to disclose moderate degrees of dehydration and/or volume depletion that previously have been difficult to explore. The prevalence and pathophysiological role of such dehydration in the preoperative setting is currently unclear. Further studies are needed to investigate whether the Hgb response to a preoperative fluid challenge can be used to refine and individualize perioperative fluid therapy.

Acknowledgements: Nurses Susanne Öster and Helén Didriksson assisted during the experiments. Statistician Elisabeth Berg, Karolinska Institutet, performed many of the data analyses. The European Society of Anesthesiology supported the project.

\section{References}

1. Nisanevich V, Felsenstein I, Almogy G, Weissman C, Einav S, Matot I. Effect of intraoperative fluid management on outcome after intraabdominal surgery. 
Anesthesiology 2005; 103: 25-32

2. Hahn RG. Volume kinetics for infusion fluids (review). Anesthesiology 2010; 113: $470-81$

3. Ståhle L, Nilsson A, Hahn RG. Modelling the volume of expandable body fluid spaces during i.v. fluid therapy. Br J Anaesth 1997: 78: 138-43

4. Hahn RG, Drobin D. Urinary excretion as an input variable in volume kinetic analysis of Ringer's solution. Br J Anaesth 1998: 80: 183-8.

5. Drobin D, Hahn RG. Volume kinetics of Ringer's solution in hypovolemic volunteers. Anesthesiology 1999; 90: 81-91

6. Drobin D, Hahn RG. Kinetics of isotonic and hypertonic plasma volume expanders. Anesthesiology 2002: 96: 1371-80

7. Ewaldsson C-A, Hahn RG. Kinetics and extravascular retention of acetated Ringer's solution during isoflurane and propofol anesthesia for thyroid surgery. Anesthesiology 2005: 103: 460-9

8. Norberg $\AA$, Hahn RG, Li H, Olsson J, Prough DS, Börsheim E, Wolf S, Minton R, Svensén $\mathrm{CH}$. Population volume kinetics predicts retention of $0.9 \%$ saline infused in awake and isoflurane-anesthetized volunteers. Anesthesiology 2007; 107: 24-32

9. Cannesson M, Desebbe O, Rosamel P, Delannoy B, Robin J, Bastien O, Lehot J-J. Pleth variability index to monitor the respiratory variations in the pulse oximeter plethysmographic waveform amplitude and predict the fluid responsiveness in the operating theatre. Br J Anaesth 2008; 101: 200-6

10. Forget P, Lois F, de Kock M. Goal-directed fluid management based on the pulse oximeter-derived pleth variability index reduces lactate levels and improves fluid management. Anesth Analg 2010; 111: 910-4

11. Soubrier S, Saulnier F, Hubert H, Delour P, Lenci H, Onimus T, Nseir S, Durochner A. Can dynamic indicators help the prediction of fluid responsiveness in spontaneously breathing critically ill patients? Intensive Care Med 2007; 33: 
$1117-24$

12. Keller G, Cassar E, Desebbe O, Lehot JJ, Cannesson M. Ability of pleth variability index to detect hemodynamic changes induced by passive leg raising in spontaneously breathing volunteers. Critical Care 2008: 12: R37

13. El-Sayed MS, Ali N, Omar AA. Effects of posture and ergometer-specific exercise modality on plasma viscosity and plasma fibrinogen: the role of plasma volume changes. Clin Hemorheol Microcirc 2011; 47: 219-28

14. Armitage P, Berry G, Matthews JNS. Statistical Methods in Medical Research. Oxford, Blackwell Science Ltd., 2001; pp. 40-4

15. Hahn RG, Li Y, Zdolsek J. Non-invasive monitoring of blood haemoglobin for analysis of fluid volume kinetics. Acta Anaesthesiol Scand 2010; 54: 1233-40

16. Drobin D, Lindahl C, Hahn RG. Volume kinetics of acetated Ringer's solution during experimental spinal anesthesia. Acta Anaesthesiol Scand 2011; 55: 987-94

17. Hahn RG, Andrijauskas A, Drobin D, Svensen C, Ivaskevicius J. A volume loading test for the detection of dehydration. Medicina 2008; 44: 953-9

18. Svensén C, Drobin D, Olsson, J, Hahn RG. Stability of the interstitial matrix after crystalloid fluid loading studied by volume kinetic analysis. Br J Anaesth 1999; 82: 496-502

19. Holte K, Hahn RG, Ravn L, Bertelsen KG, Hansen S, Kehlet H. The influence of liberal vs. restrictive fluid management on the elimination of a postoperative intravenous fluid load. Anesthesiology 2007; 106: 75-9

20. Norberg A. Measurement of body fluids in vivo. In: Hahn RG, Prough DS, Svensen CH, eds: Perioperative Fluid Therapy. New York, Informa Healthcare, 2007: $1-11$

21. Svensén CH, Olsson J, Hahn RG. Intravascular fluid administration and hemodynamic performance during open abdominal surgery. Anesth Analg 2006: 103: 671-676.

22. Bundgaard-Nielsen M, Jorgensen CC, Secher NH, Kehlet H. Functional 
intravascular volume deficit in patients before surgery. Acta Anaesthesiol Scand 2010; 54: 464-9

23. Broch O, Bein B, Grunewald M, Höcker J, Schöttler J, Meybohm P, Steinfath M, Renner J. Accuracy of the pleth variability index to predict fluid responsiveness depends on the perfusion index. Acta Anaesthesiol Scand 2011: 55: 686-93.

24. Guyton AC, Hall JE. Textbook of Medical Physiology, $9^{\text {th }}$ Edition. Philadelphia, WB Saunders Company, 1996; p. 370

25. Drobin D. A single-model solution for volume kinetic analysis of isotonic fluid infusions. Acta Anaesthesiol Scand 2006; 50:1074-80

26. Li Y, Hahn RG, Hu Y, Xiang Y, Zhu S. Plasma and renal clearances of lactated Ringer's solution in pediatric and adult patients just before anesthesia is induced. Pediatric Anesthesia 2009: 19: 682-7

27. Li Y, Zhu HB, Zheng X, Chen HJ, Shao L, Hahn RG. Low doses of esmolol and phenylephrine act as diuretics during intravenous anesthesia. Crit Care 2012; 16 : R18 
Table 1. Flow diagram for Experiments (1) to (4) performed in 10 volunteers.

Measurements are marked in blue.

Exneriment

\begin{tabular}{|c|c|c|c|c|c|}
\hline (1) & \multirow{4}{*}{$\begin{array}{c}\text { Drink } 800 \mathrm{ml} \\
\text { tap water, free } \\
\text { voiding }\end{array}$} & \multirow{4}{*}{$\begin{array}{c}\text { Fluid } \\
\text { recruit- } \\
\text { ment } \\
\text { test } \\
\text { (pulse } \\
\text { oximetry) }\end{array}$} & $\begin{array}{c}\text { Infusion } 5 \mathrm{ml} / \mathrm{kg} \\
\text { (Invasive } \mathrm{Hb} \text { ) }\end{array}$ & \multirow{4}{*}{$\begin{array}{c}\text { Fluid } \\
\text { re-cruitment } \\
\text { Test } \\
\text { (pulse oximetry) }\end{array}$} & \\
\hline (2) & & & $\begin{array}{c}\text { Infusion } 10 \mathrm{ml} / \mathrm{kg} \\
\text { (Invasive } \mathrm{Hb} \text { ) }\end{array}$ & & \\
\hline (3) & & & \multirow[t]{2}{*}{ Dehydration } & & $\begin{array}{c}\text { Infusion } 5 \mathrm{ml} / \mathrm{kg} \\
\text { (Invasive } \mathrm{Hb} \text { ) }\end{array}$ \\
\hline \multirow[t]{2}{*}{ (4) } & & & & & $\begin{array}{c}\text { Infusion } 10 \mathrm{ml} / \mathrm{kg} \\
\text { (Invasive } \mathrm{Hb} \text { ) }\end{array}$ \\
\hline & 7 & & 10 & 11 & 12 \\
\hline
\end{tabular}

Hour of the day 


\section{Table 2}

Optimal estimates of the kinetic parameters when the one-volume model was used to analyze all data, when the statistically justified volume kinetic model (one- or two-volume model) according to the $F$ test was applied, and when the collected urine was used, depending on whether or not the experiment was preceded by a dehydration procedure. Symbols are defined in Fig. 1 and the data are the median $\left(25^{\text {th }}-75^{\text {th }}\right.$ percentiles $)$ for the group.

\begin{tabular}{|c|c|c|c|}
\hline & Euhydration & Dehydration & Statistics* \\
\hline \multicolumn{4}{|c|}{ One-volume model only } \\
\hline & $\mathrm{n}=20$ & $\mathrm{n}=20$ & \\
\hline$V_{\mathrm{c}}(\mathrm{ml} / \mathrm{kg})$ & $60(45-70)$ & $62(55-72)$ & \\
\hline$C l(\mathrm{ml} / \mathrm{min} / \mathrm{kg})$ & $1.84(1.23-2.57)$ & $0.53(0.41-0.79)$ & $P<0.001$ \\
\hline$T^{1 / 2}$ (minutes) & $23(12-37)$ & $76(57-101)$ & $P<0.001$ \\
\hline \multicolumn{4}{|l|}{ Optimal model } \\
\hline One-volume & $\mathrm{n}=14$ & $\mathrm{n}=4$ & \\
\hline$V_{\mathrm{c}}(\mathrm{ml} / \mathrm{kg})$ & $56(43-69)$ & $62(54-72)$ & \\
\hline$C l(\mathrm{ml} / \mathrm{min} / \mathrm{kg})$ & $2.21(1.33-2.80)$ & $0.54(0.45-0.70)$ & $P=0.044$ \\
\hline Two-volume & $\mathrm{n}=6$ & $n=16$ & \\
\hline$V_{\mathrm{c}}(\mathrm{ml} / \mathrm{kg})$ & $35(30-49)$ & $36(31-44)$ & \\
\hline$V_{\mathrm{p}}(\mathrm{ml} / \mathrm{kg})$ & $49(38-59)$ & $48(38-69)$ & \\
\hline $\mathrm{Cl}(\mathrm{ml} / \mathrm{min} / \mathrm{kg})$ & $0.83(0.63-1.13)$ & $0.23(0.03-0.41)$ & $P<0.001$ \\
\hline$C l_{\mathrm{d}}(\mathrm{ml} / \mathrm{min} / \mathrm{kg})$ & $3.6(2.9-5.4)$ & $2.7(1.7-3.4)$ & \\
\hline Pooled optimal & $\mathrm{n}=20$ & $\mathrm{n}=20$ & \\
\hline $\mathrm{Cl}(\mathrm{ml} / \mathrm{min} / \mathrm{kg})$ & $1.65(1.01-2.57)$ & $0.32(0.09-0.45)$ & $P<0.001$ \\
\hline$T^{1 / 2}(\min )$ & $21(13-33)$ & $82(70-135)$ & $P<0.001$ \\
\hline Urine-based kinetics & $\mathrm{n}=18$ & $\mathrm{n}=20$ & \\
\hline$C l_{\mathrm{r}}(\mathrm{ml} / \mathrm{min} / \mathrm{kg})$ & $1.67(1.11-3.10)$ & $0.42(0.27-0.82)$ & $P<0.001$ \\
\hline Excreted/Infused (percent) & $73(52-129)$ & $49(36-82)$ & $P=0.037$ \\
\hline
\end{tabular}

* Wilcoxon's matched-pair test when the number of patients in the groups are equal, else the Mann-Whitney's test. 


\section{Table 3}

Sensitivity and specificity of kinetic parameters that detected dehydration

when $5 \mathrm{ml} / \mathrm{kg}$ of acetated Ringer's was infused.

\begin{tabular}{|c|c|c|c|c|}
\hline Parameter & $\begin{array}{l}\text { Data } \\
\text { points } \\
(\mathrm{n}=)\end{array}$ & Cut-off point & $\begin{array}{l}\text { Sensitivity, \% } \\
\text { (lower 95\% CI) }\end{array}$ & $\begin{array}{l}\text { Specificity, \% } \\
\text { (lower 95\% CI) }\end{array}$ \\
\hline
\end{tabular}

\section{Blood data}

$\begin{array}{llccrc}T_{1 / 2} & \text { One-volume model } & 16 & >40 \mathrm{~min} & 100(66) & 100(66) \\ & \begin{array}{l}\text { Pooled optimal model* } \\ \text { One-volume model }\end{array} & 16 & >40 \mathrm{~min} & 100(66) & 100(66) \\ & & & >45 \mathrm{~min} & 90(54) & 90(54) \\ & & & & & \\ \mathrm{Cl} & \text { One-volume model } & 16 & <1.1 \mathrm{ml} / \mathrm{min} / \mathrm{kg} & 100(66) & 100(66) \\ & & 4 & <0.8 \mathrm{ml} / \mathrm{min} / \mathrm{kg} & 91(57) & 100(63)\end{array}$

Hgb difference

$\begin{array}{lllll}60 \text { min - baseline } & 2 & >2.2 \% & 100(63) & 90(57) \\ \text { Mean 60/70 - baseline } & 3 & >2.2 \% & 100(63) & 90(57)\end{array}$

\section{Urine data}

$\begin{array}{lcccc}\mathrm{Cl}_{\mathrm{r}} & 17 & <1.4 \mathrm{ml} / \mathrm{min} / \mathrm{kg} & 100(66) & 90(54) \\ \text { Excreted/Infused volume } & 1 & <95 \mathrm{percent} & 72(39) & 78(40)\end{array}$

$T_{1 / 2}=$ half-life; $\mathrm{Cl}=$ elimination clearance; $C l_{\mathrm{r}}=$ renal clearance.

Sixteen data points comprise $0,5,10,15,20,25,30,35,40,45,50,60,70,90,105$, and $120 \mathrm{~min}$.

Four data points comprise $0,15,60$, and $70 \mathrm{~min}$.

$*=$ as determined by the $F$ test. 


\section{Legends to figures}

Fig. 1. The one- and two-volume kinetic models used to analyze the data (top) and the definitions and units of the input and output variables and parameters (bottom). Flow parameters are shown in blue and volumes in red.

Fig. 2. Parameters that distinguish between euhydration and dehydration. The $5 \mathrm{ml} / \mathrm{kg}$ volume of Ringer's solution (blue symbols) offered the best separation, as marked by the green line. Each point is one experiment, arranged from lowest to highest value, depending on whether the kinetics were analyzed according to the one-volume model (A and B) or with the optimal model (C). Half-lives $\geq 175$ min were represented on the graph by that value.

Fig. 3. The fractional dilution of venous plasma during and after infusion of $5 \mathrm{ml} / \mathrm{kg}(\mathbf{A}$ and $\mathbf{B}$ ) and $10 \mathrm{ml} / \mathrm{kg}(\mathbf{C}$ and $\mathbf{D})$ of acetated Ringer's solution during $15 \mathrm{~min}$ in 10 volunteers in the euhydrated (A and $\mathbf{C}$ ) and dehydrated (B and $\mathbf{D})$ state. Green lines indicate individual experiments where the fractional plasma dilution was calculated as $[(\mathrm{Hgb} / \mathrm{Hgb}(\mathrm{t}))-1] /(1-\mathrm{Hct}) ; \mathrm{Hgb}$ and Hct are the hemoglobin concentration and the hematocrit at baseline, respectively, and $\mathrm{Hgb}(\mathrm{t})$ is the hemoglobin concentration at a later time $(\mathrm{t})$. The thick blue line is the modeled curve based on the kinetic parameters for the statistically justified (optimal) model, as shown in Table 2.

Fig. 4. Predicted dilution of venous plasma over time based on the kinetic parameters for the statistically justified kinetic model in each one of 40 experiments in which 10 volunteers received either $5 \mathrm{ml} / \mathrm{kg}$ (A) or $10 \mathrm{ml} / \mathrm{kg}$ (B) over $15 \mathrm{~min}$ when being in the euhydrated and dehydrated state. The greatest difference in plasma dilution between the dehydrated and euhydrated state was reached after approximately 60-70 $\min (\mathbf{C}$ and $\mathbf{D})$. 
Fig. 5. Pulse oximeter indices during the fluid recruitment maneuver involving a change of body position from semi-standing to lying down at $10 \mathrm{~min}$. Mean (SD) values comprising (A) the perfusion index, (B) Hgb concentration, and (C) the pleth variability index (PVI) from 40 tests. Half of the tests were performed shortly after dehydration of 1.7 L (mean) with furosemide. Open squares=euhydration, filled circles=dehydration. 

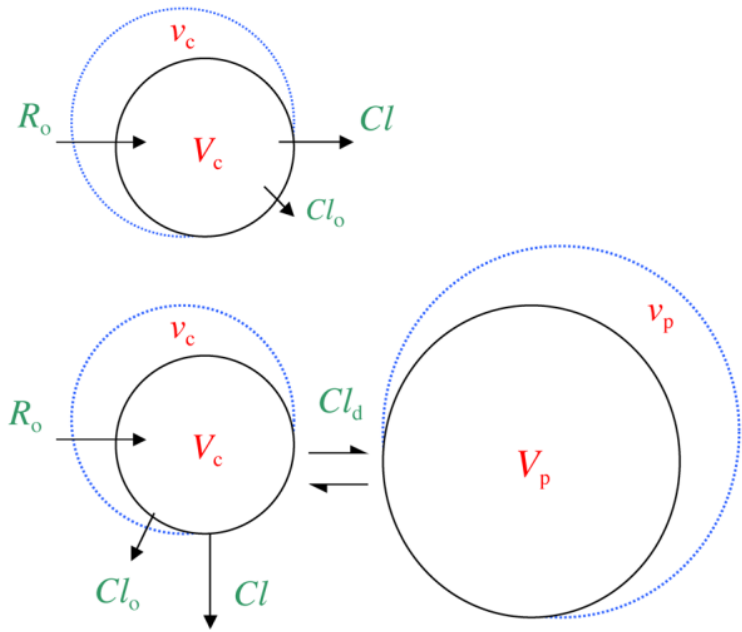

\begin{tabular}{clc}
\hline $\begin{array}{c}\text { Variable or } \\
\text { Parameter }\end{array}$ & Definition & Unit \\
\hline & & \\
INPUT & & $\mathrm{ml} / \mathrm{min}$ \\
$R_{0}$ & rate of infusion & $\mathrm{g} / \mathrm{dL}$ \\
$\mathrm{Hgb}$ & blood hemoglobin concentration at baseline & $\mathrm{g} / \mathrm{dL}$ \\
$\mathrm{Hgb}(\mathrm{t})$ & blood hemoglobin concentration at a later time $t$ & $\mathrm{ml} / \mathrm{min}$
\end{tabular}

\section{OUTPUT}

One-volume model

\begin{tabular}{|c|c|c|}
\hline$v_{c}(t)$ & expanded size of $V_{c}$ at time $t$ & $\mathrm{~L}$ \\
\hline$V_{c}$ & $\begin{array}{l}\text { volume of the body fluid space expanded by } \\
\text { infused fluid at baseline }\end{array}$ & $\mathrm{L}$ \\
\hline \multicolumn{3}{|c|}{ Two-volume model } \\
\hline$v_{c}(t)$ & expanded size of central fluid space at time $t$ & $\mathrm{~L}$ \\
\hline$v_{p}(t)$ & expanded size of peripheral fluid space at time $t$ & $\mathrm{~L}$ \\
\hline$V_{c}$ & volume of central body fluid space at baseline & $\mathrm{L}$ \\
\hline$V_{p}$ & volume of peripheral body fluid space at baseline & $\mathrm{L}$ \\
\hline$C l_{\mathrm{d}}$ & distribution clearance & $\mathrm{ml} / \mathrm{min}$ \\
\hline \multicolumn{3}{|c|}{ Both kinetic models } \\
\hline $\mathrm{Cl}$ & elimination clearance of infused fluid & $\mathrm{ml} / \mathrm{min}$ \\
\hline $\mathrm{Cl}_{\mathrm{r}}$ & renal clearance of infused fluid & $\mathrm{ml} / \mathrm{min}$ \\
\hline$T_{1 / 2}$ & half-life of the infused fluid & $\min$ \\
\hline
\end{tabular}

Rate parameters may also be expressed as $\mathrm{m} / \mathrm{min} / \mathrm{kg}$ body weight. 
One-volume model
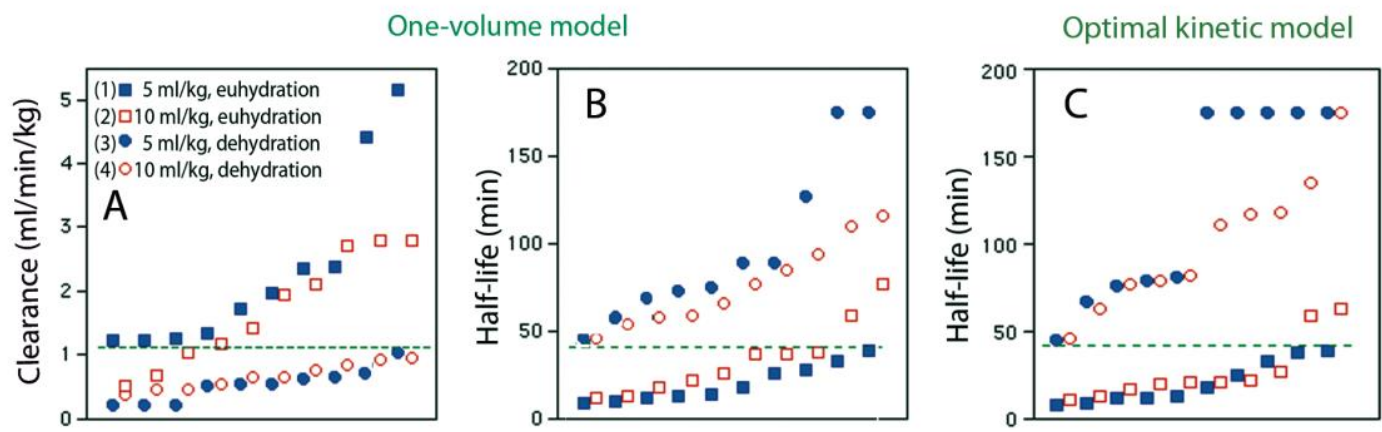

The 10 subjects arranged in order of increasing half-life or clearance

Fig. 2

Euhydration

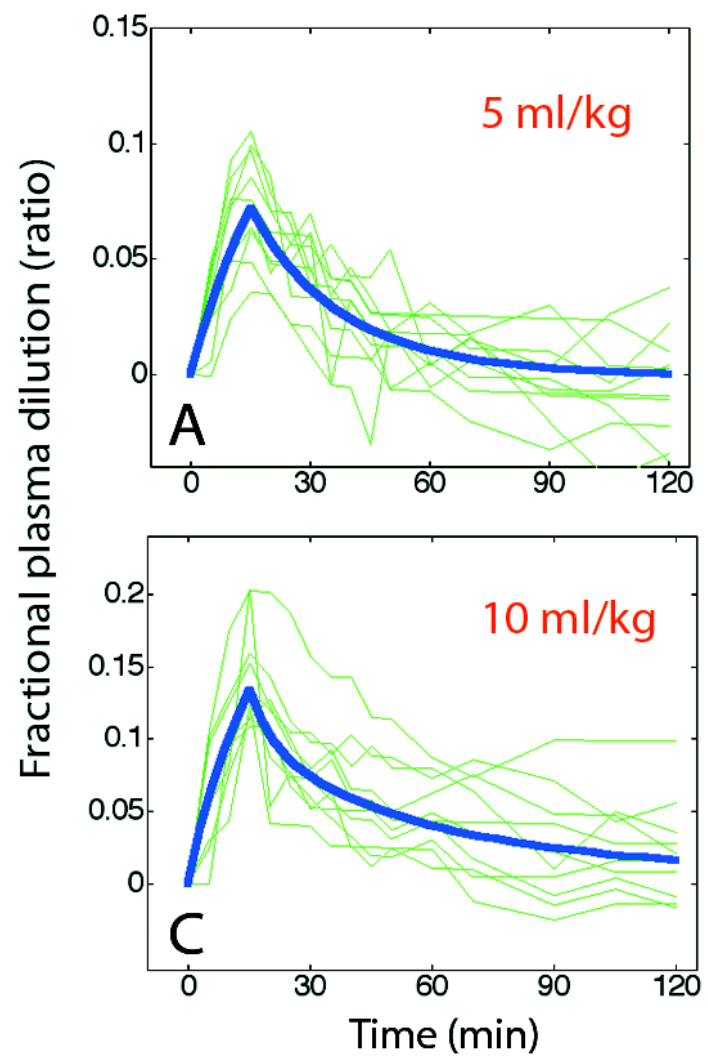

Dehydration
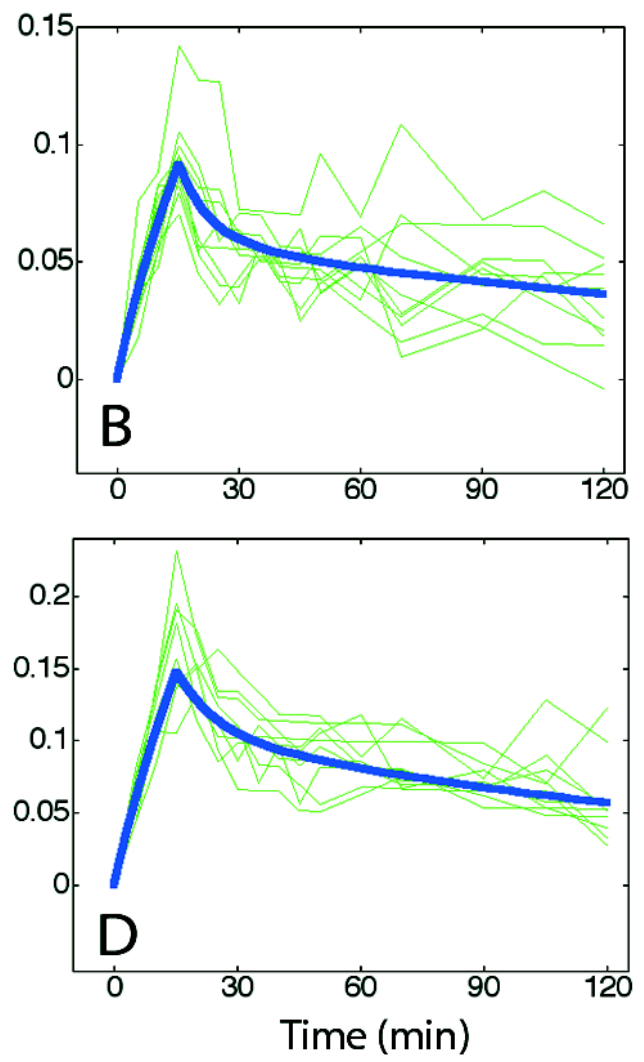

Fig. 3 

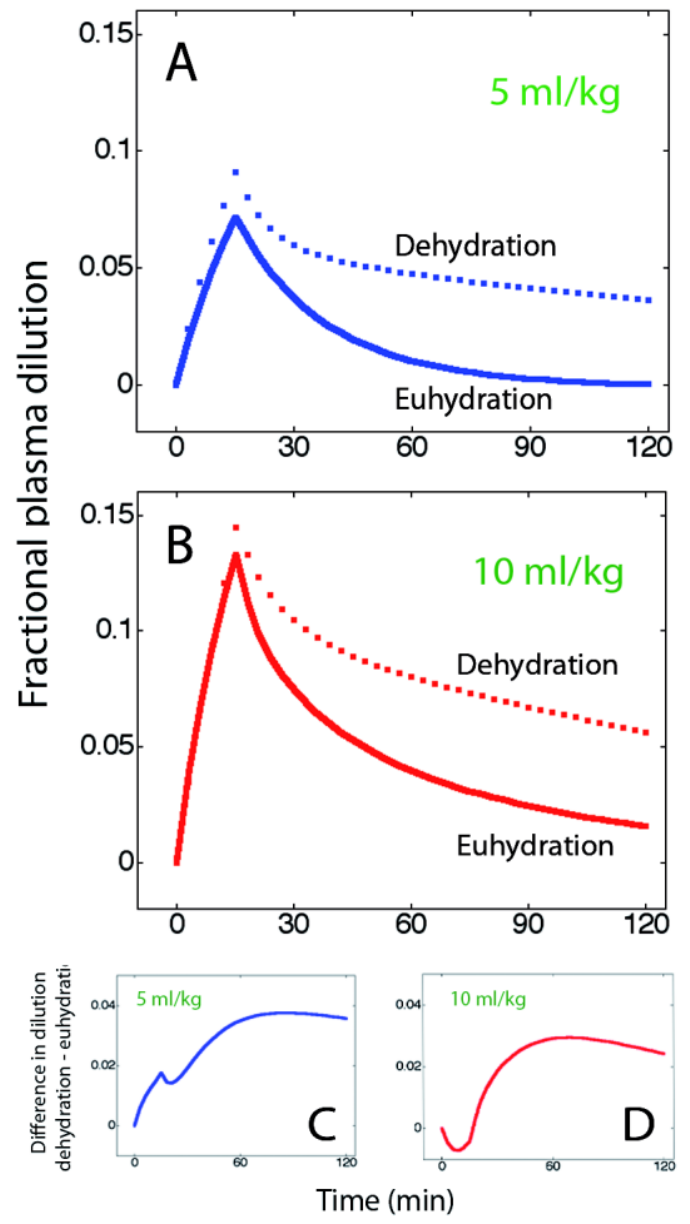

Fig. 4 


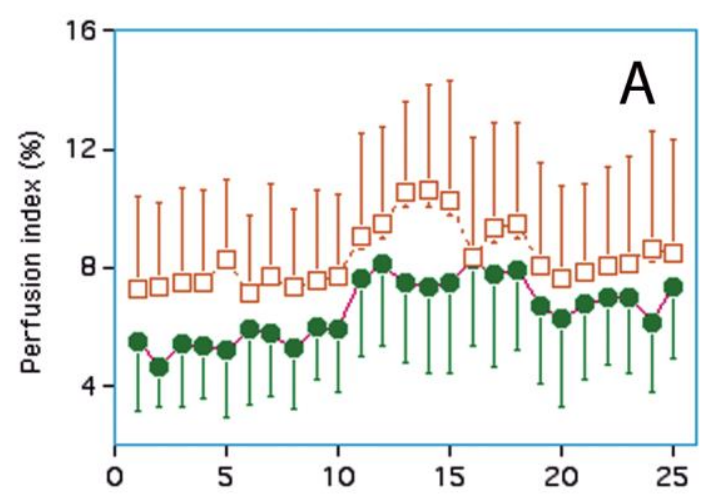

-.-‥- Euhydration $\longrightarrow$ Dehydration
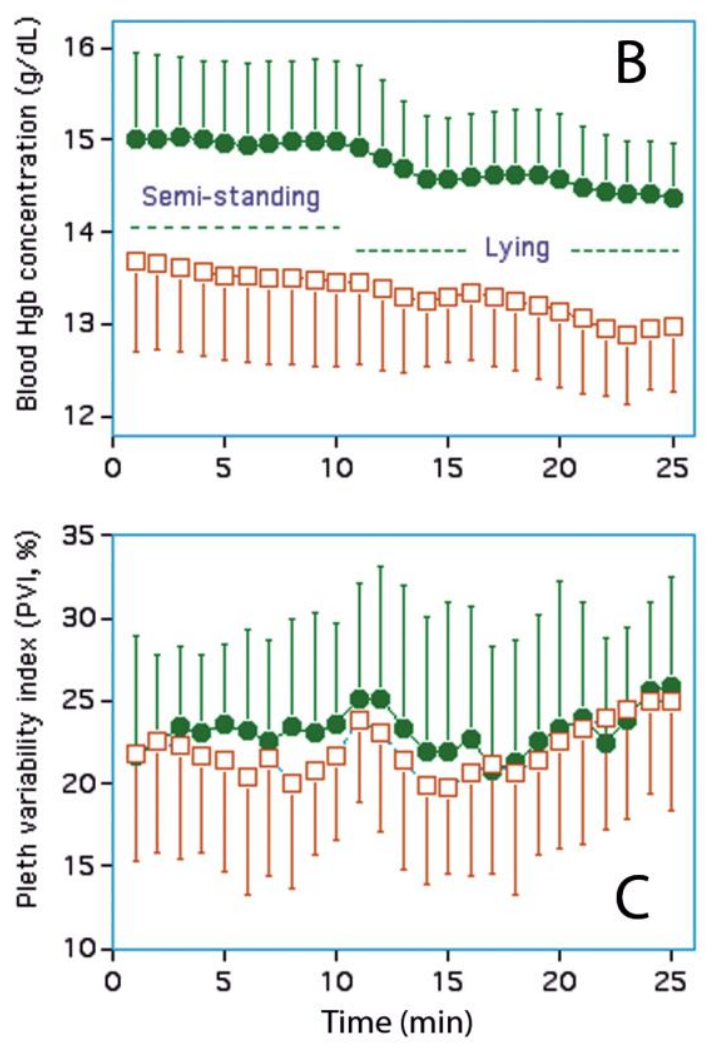

Fig. 5 